\section{William G. Bradley Jr, MD, PhD, FACR}

$\mathbf{P}$ erhaps more than any other single figure, Bill Bradley (19482017) both educated us regarding clinical MR imaging and popularized clinical MR imaging during its early days in setting the trajectory of the field. Bill was a larger-than-life figure with magnums of charisma, ebullience, and brilliance in such a unique blend that his passing leaves an undeniable gaping void in our collective family. Bill is survived by his devoted wife, pediatric neuroradiologist Dr Rosalind Dietrich; his son David; daughters Kristin Egan, India Homsy, and Felicity; and 5 grandchildren. Bill is also survived by his 2 brothers, Drs John Bradley and Thomas Bradley, and 6 nieces and nephews.

Bill was a self-proclaimed "Air Force brat," born in Los Angeles on July 30, 1948, to Shirley Ann Premack and flight surgeon Dr William G. Bradley, Sr. He was an inveterate traveler, an unparalleled raconteur, and a remarkable creative force. Bill loved people, places, single malt scotch, laughing, and innovating. Bill left behind legions of fellows, residents, industry friends, and other acquaintances who consistently volunteer that he influenced, entertained, befriended, enriched, counseled, and guided them. Bill was irrepressible and uniquely unforgettable.

Bill lived his early years in Japan, was a proud Eagle Scout at 13, and graduated from high school in Bitberg, Germany, as Class President. Bill was an insatiable reader and learner and a lover of all things scientific from a very early age. His curiosity and creativity were manifest in his adolescent and teenage years by brilliant and innovative contributions to science fairs. Bill's love of science and discovery was, in part, satisfied by his bachelor's degree from the California Institute of Technology and his subsequent doctorate from Princeton, both in chemical engineering, as he sought the means to apply science and discovery for the common good. Bill found the means in medicine.

Bill completed his medical degree and radiology training at the University of California, San Francisco (UCSF), where radiology allowed his love of technology and science to simultaneously flourish. Bill's insatiable curiosity and brilliance were focused and encouraged by his mentor and chair, Alex Margulis. Dr Margulis tasked Bill with making something practical of MR imaging, which at the time was a promising-yet-unproved new addition to the growing pantheon of imaging. At UCSF, Bill focused on translating and practically interpreting the complex physics of MR imaging into a language that other physicians could understand. Bill was equipped to handle this task by dint of his Cal Tech and Princeton training and his belief in the potential of the technology. Bill succeeded through his seminal landmark text written and edited with his friend David Stark, a brilliant radiologist in Boston at the time. This textbook led and taught the field for decades.

Bill's mind was in perpetual motion, and the breadth of his curiosity and prodigious intellectual appetite encompassed such clinically and scientifically vital topics such as hydrocephalus, CSF flow, multiple sclerosis, blood breakdown products, and brain lymphatics and flow, among many topics. Bill pursued the science and phenomenology of MR imaging with unflagging determination and boundless energy during the next 3 decades. He initially

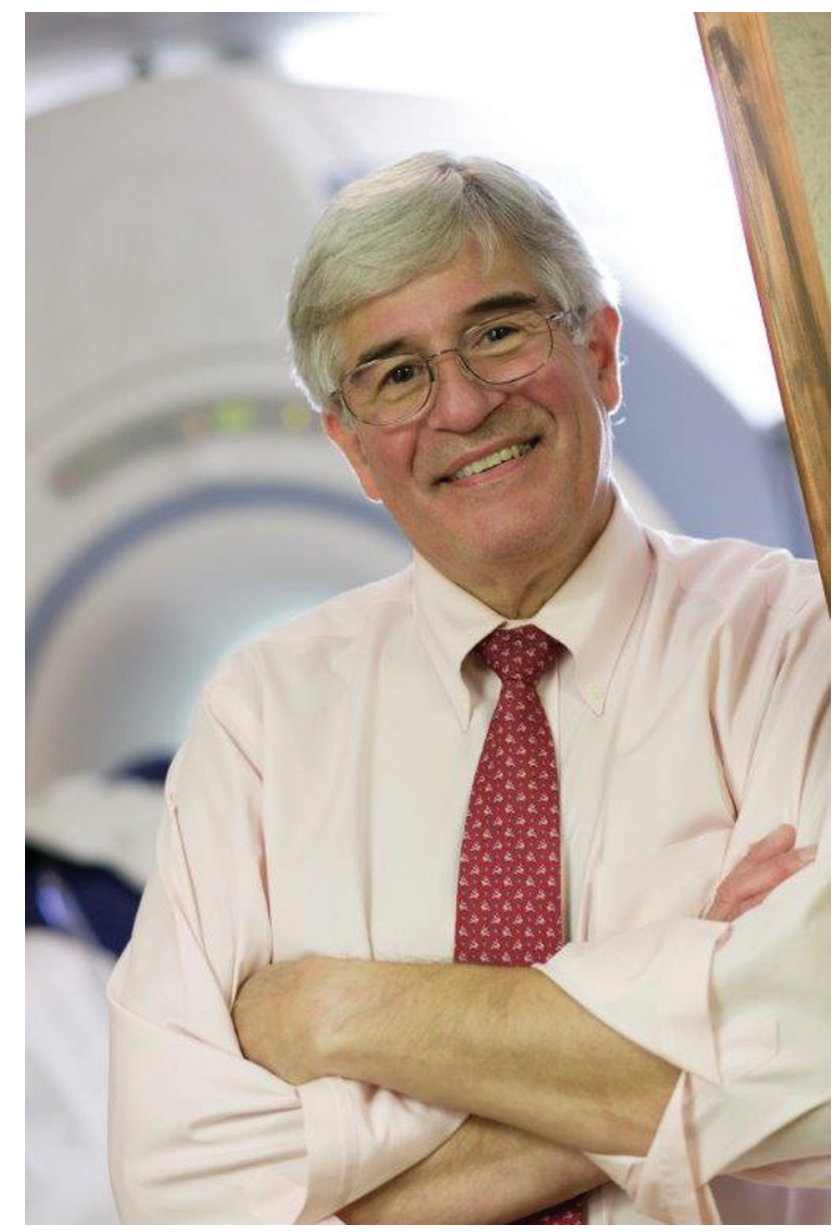

chose to discover and investigate in private practice settings. Bill joined Huntington Memorial Hospital in Pasadena, California, and then Long Beach Memorial Hospital, Long Beach, California, transforming both institutions with his delightful touch and his keen intellect. In private practice, Bill proved the headroom for discovery and novel implementation outside traditional academic centers while training outstanding fellows who would popularize and establish MR imaging. In private practice, Bill was a 1-man university, pursuing discovery, innovation, teaching, and clinical practice at a level that was the envy of fully established and broadly staffed world-class academic radiology departments.

In 2002, Bill started a new chapter in his professional life. Across the years, Bill's insatiable thirst for knowledge, his unique ability to connect individuals, and his extroversion drew him to true university settings, where he could interact with engineers and scientists on a more sustained basis and deliver innovation as an expected and central product of his work. Bill enthusiastically accepted the charge of leading the Radiology Department at the University of California, San Diego, which he did for the next 13 years. During the first 8 years of his chairmanship, Bill intentionally and thoughtfully improved the rating of the radiology department in terms of National Institutes of Health funding from the mid-40s to the number 8 position. He achieved this by establish- 
ing a team of world-famous faculty members within the department and as a brilliant talent scout, through identifying and recruiting inevitable future field leaders. Bill possessed a unique and infectious vision of the future and was able to share this vision with numerous industrial partners. Despite the competitive relationships among the industrial giants supplying radiology, Bill's charisma and imagination were such that he was central to all the vendors' conversations regarding their individual futures, whether the industrial friends were world leaders or new on the scene.

Attempting to quantify Bill's achievements is challenging because any such accounting fails to effectively convey his singular charisma and the subjective nature of his enduring impact on our field through each of us who knew and loved him. In addition, a distinguished Professor Emeritus, Bill published more than 200 articles, 54 chapters, and 20 additional textbooks. His accomplishments and service to organized radiology resulted in a collection of gold medals for distinguished and exceptional lifetime achievements from the most prestigious radiology societies, of which Bill was rightfully proud and grateful. Bill's gold medals were awarded by the Radiological Society of North America, the American College of Radiology, the International Society of Magnetic Resonance in Medicine, the American Roentgen Ray Society, and the Association of University Radiologists. For an individual to receive all 5 medals is truly exceptional and a testament to Bill's service and enduring impact on our field.
Bill's extensive contributions included his serving as President of the International Society of Magnetic Resonance in Medicine and serving on the Board of Trustees of the Radiological Society of North America Research and Education Foundation (1995-2001) and as the Chairman of the Fund Development Committee of that organization from 1996 to 2008. Bill was on the Board of Chancellors of the American College of Radiology, where he chaired the Commission on Neuroradiology and MR imaging from 1999 to 2005 and served as Vice President from 2005 to 2006. Bill was Chair of the Steering Committee for the Coalition for Imaging and Bioengineering Research and on the Boards of the Academy of Radiology Research, Association of University Radiologists, International Society for Strategic Studies in Radiology, and Academy of Radiology Leadership and Management. A simple tabulation of his offices fails to fully convey the impact and influence he had on every one of these organizations.

As with his other contributions, quantitating Bill's effect on organized radiology is akin to capturing lightning in a bottle. In pushing the analogy, even though the rest of us would never consider capturing lighting in a bottle, I imagine my friend Bill would be captivated by the idea, would imagine and iterate through myriad ways of doing just that, and would ultimately succeed. That, exactly, was our friend Bill.

A. Norbash

http://dx.doi.org/10.3174/ajnr.A5712 